\title{
Research in the Impact of Dynamic Loads for the Development of Pentice Designs when Sinking Skip Shafts
}

\author{
Vladimir Pershin ${ }^{1}$, Aleksandr Kopytov ${ }^{1}$, and Ahmed Wetti $^{1}$ \\ ${ }^{1}$ T.F. Gorbachev Kuzbass State Technical University, 650000, 28 street Vesennyaya, Kemerovo, \\ Russian Federation
}

\begin{abstract}
In order to protect workers engaged in shaft sinking works artificial protective equipment (buntons) with the support element from powerful I-beams or truss structures are used. They have to withstand enormous push loading, be strong, simple in design, have less labor input during construction and dismantling. Under shaft sinking in case of skip operational winding performance, a protective bunton can be exposed to the rock mass flow in the event of an emergency full skip run. To substantiate the variables and develop the design of pentices when sinking an active hoisting shaft, the skip falls time dependence on the changes in its fall height, taking into account the velocity and the air stream direction in the shaft, was established using mathematical modeling. LLC "SibGorComplexEngineering" together with the Department of Construction of Underground Structures and Mines of T.F. Gorbachev Kuzbass State Technical University have developed several new designs variants of protective buntons for vertical shafts sinking in case of operational winding performance. It is a Z-shaped structure of the offset in height, parallel to each other of upper and lower protective buntons, bushed with sloped reflective metal sheets and it is interconnected by a vertical division wall.
\end{abstract}

\section{Introduction}

Mineral resources are the most important potential for innovative development of the Russian economy. Mining geotechnology must ensure their high competitiveness in market economy. Solving this problem requires special approaches in making new technical solutions and process designs to increase the efficiency and safety of underground mining operations [1].

In domestic and foreign underground mining practices, shaft mining is widely used; the depth of shafts being more than $3 \mathrm{~km}$.

A large number of various machinery and equipment are used during vertical shaft construction and operation. Taking into account this fact, their standard cross-section with shaft vehicles, reinforcement and equipment based on the minimization of standard sizes, reliability, safety and ease of operation, were developed.

As a rule, a mining enterprise in accordance with the design, in order to maintain or increase the production capacity and maximize the extraction of minerals from the property, 
goes through several stages of reconstruction during the entire life cycle. This requires less financial expenditures and labor resources than the construction of new enterprises.

Bunton design allows reducing the impact of push loading due to direction changing and kinetic energy reduction of falling bodies. Industrial testing of a new construction of wedge protective buntons proved their high reliability, efficiency and safety of operations under shaft sinking "Skipovoiy" of Gorno-Shoria branch of OJSC "Evrazruda".

\section{Results}

Vertical shafts and their sinking are the most important segment of construction and reconstruction of mining enterprises, since only after their completion it is possible to carry out development work on the next mining level to extract new reserves, which are often richer in the content of commercial component.

When sinking an active hoisting shaft, to protect workers in its part that is being sunk from the possible fall of mine vehicles or their contents, it is necessary to construct pentices that can completely bridge over a shaft cross-section or a part of it and must withstand a heavy impact load, and also be strong, simple in design, require less labor for their construction and subsequent dismantling $[1,2]$.

Pentices are divided into three types depending on the main carrier [3]:

- natural (rock pillars);

- artificial, made of metal, concrete, reinforced concrete, steel ropes and other materials;

- combined, representing a combination of artificial pentices.

The experience of reconstruction of the Kuzbass mines shows that artificial pentices are most common for vertical circular shaft sinking.

In each case, the structural elements of a pentice, the main ones of which are horizontal support beams, are calculated on the basis of the purpose and the specifications established for sinking operations.

The analysis of the vertical shaft sinking experience shows that most designs propose to use artificial horizontal pentices with a support element made of powerful H-beams or truss structures bridging over a shaft cross-section.

The most stringent requirements are imposed upon the calculation of structural elements of pentices and their construction when sinking skip-hoisting shafts.

This pentice must withstand the heavy dynamic impact in the event of the full skip run or the spillage of its contents, and the design - provide the possibility of its construction in the shortest possible time in order to reduce the shaft stoppage time and avoid a decline in an enterprise's output capacity.

In terms of the possible load on pentices, skip shafts can be:

- unbalanced hoisting;

- multi-rope hoisting;

They are characterized by the following types of dynamic impact on a pentice:

- full skip run;

- emergency skip self-dumping.

Shafts of most modern mines are equipped with powerful multi-rope skip hoisting equipment. Simultaneous run of ropes and drop of a full skip in this case is almost excluded. So, during the active hoisting shaft sinking, a pentice is constantly exposed to the impact of separately falling pieces, and can also be subjected to the dynamic impact of rock mass flow in the event of emergency skip self-dumping.

Calculating the impact on a pentice in the case of emergency skip self-dumping when sinking the active hoisting shaft, we adopted the technique developed for the Krivbass mines, which makes it possible to determine the probabilistic value of the dynamic load of 
rock mass flow onto a pentice completely bridging over a face on the level of the crosssection of the shaft part that is being sunk.

The flow of rock pieces falling on a pentice during skip self-dumping is a variable-mass body, which for some time $\Delta t$ increases from zero to the final value. The method of determining the impact force action on pentices is based on the design model that presents the flow of loose rock pieces in the form of a variable-mass body, and the collision process - in the form of a short impulse of the impact force acting on a pentice. The process of the impact force action on a pentice can be divided into three interrelated stages: the skip selfdumping, the fall of rock pieces into the shaft and the direct impact.

On the basis of the conducted studies and the mathematical modeling, it was found that the value of the impact on a pentice increases exponentially. In turn, the dynamic load and the body fall velocity increase directly in proportion as a logarithmic function of the height of the fall. Thus, a change in the magnitude of the flow coefficient $\chi$, taken as a function of the broken ore size, affects the force of collision of bodies against a pentice. The optimum broken ore size is, in this case, the value not exceeding $0.2 \mathrm{~m}$ in diameter.

Calculations of pentice elements using this methods show that for complete bridging over the shaft part that is being sunk in one level, great labor costs and material consumption will be required, especially for the construction of horizontal support beams.

The zero-height fall of vehicles is also possible when the active hoisting shaft is being sunk. With this type of accident, a pentice experiences the highest dynamic loads.

The determination of the falling vehicle velocity at the moment of its collision with the surface of a pentice is particularly important for solving pentice stability problems. The methods for determining the free fall velocity in airless space, depending on the height of the fall, or the fall velocity determination, taking into account the air resistance, are widespread. The constraint of the space in which the fall occurs is not taken into account. In this case, all types of air resistance, except for the drag resistance, are also not taken into account, and its value is determined using the drag coefficient $C_{x}$ [4]. The $c_{x}$ values taken as $1-1.1$ provide solutions that are $95-100 \%$ identical to the classical solution of mechanics concerning the free fall of the body, taking into account the air space of unlimited size. However, it is known that the area of the flow expulsion by the falling body in the limited space is larger than the area of the mid-section of the body itself. This leads to an increase in local velocities and to a significant increase of $C_{x}$. Thus, $C_{x}$ will be significantly more than the accepted values for the vehicles fall in the shaft [5].

The value of the velocity of the vehicle's free fall at the moment of the impact has a significant effect on the dynamic loading value, and, consequently, the stability of pentices. It is well known that the velocity of the fall of the vehicles in the shaft will be less than the theoretical one. It is caused by a number of factors, both mechanical and aerodynamic. Mechanical factors are practically impossible to predict and should be attributed to the safety factor. In fact, when bodies fall at high velocities in a limited space, the total air resistance value is a variable value depending on the fall velocity and it is rather difficult to describe it. When taking into account the air resistance to the run vehicle fall, it is necessary to consider it as the force acting in the direction opposite to the motion. In this case, the problem of determining the variables of the motion of the vehicle that has run in the shaft is solved, taking into account the limited space and the direction of the ventilation air flow. In this case, two cases of motion are presented, shown in Figure 1 [6]:

a) the direction of the falling vehicle motion does not coincide with the ventilation flow direction;

b) the direction of the falling vehicle motion coincides with the ventilation flow direction. 
a)

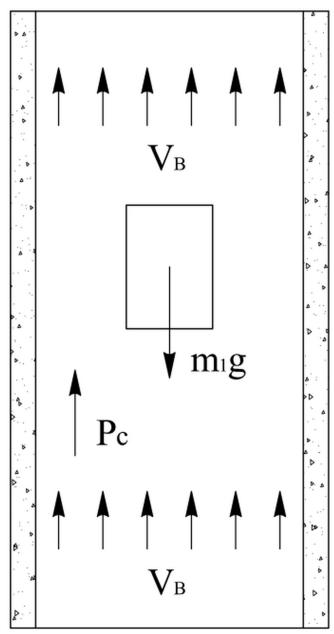

b)

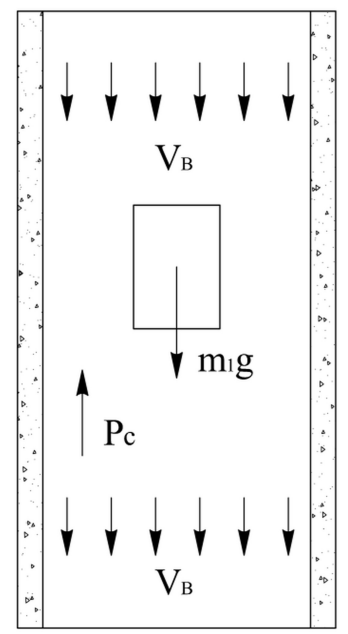

Fig. 1. A force diagram for the vehicle's free fall in a vertical shaft, in details: a - the ventilation flow is directed against the falling motion; $b$ - the ventilation flow follows the falling motion.

It is possible to determine the value of the velocity of the fall of the vehicles in the shaft, taking into account the aerodynamic resistance to the motion that occurs in the limited air space. This resistance significantly affects the fall velocity value, and, consequently, the dynamic loads. It is most often determined by the drag coefficient. The calculation of this coefficient is difficult and its values do not provide sufficient accuracy of solutions. The value of the limited air space resistance for the vehicle's free fall can be determined more precisely by the analytical method based on the synthesis of the solutions of mine aerodynamics and mathematical physics. The technique developed for the Krivbass mines, which makes it possible to fully appreciate the nature of the body motion in the air flow limited by the walls of the vertical shaft, was used for the more accurate determination of the velocity and the value of the kinetic energy of the falling body.

In accordance with the proposed methods [7], we performed calculations to determine the fall time, the kinetic energy and the velocity (Figure 2) values depending on the skip fall height within the framework of the implementation of the project of sinking "Skipovoy" shaft of Sheregesh mine of Gorno-Shorsky branch of OJSC "Evrazruda" [8-10].

\section{Conclusion}

To substantiate the variables and develop the design of pentices when sinking an active hoisting shaft, the skip fall time dependence on the changes in its fall height, taking into account the velocity and the air stream direction in the shaft, was established using mathematical modeling. The following dependences were established (Figure 2):

1. The air stream velocity being increased; the skip fall time is described by cubic function. When the air stream direction is changed, the time spent on the passage of the same section with a skip increases 1.4 times for a loaded skip weighing 50 tons, and 2.1 times for an empty skip weighing 16.6 tons.

2. The kinetic energy of the falling skip varies logarithmically and depends on the fall height, the air stream direction and velocity, as well as its (skip's) mass and the ratio of the areas of the skip mid-section to the total cross-sectional area of the shaft. 
3. The velocity of the falling skip logarithmically depends on the fall height (see Figures 2.a, 2.b, 2.c). At the same time air resistance in deep shafts provides a significant reduction in the fall velocity. The ratio of the mid-section of the skip to the cross-sectional area of the shaft has the greatest influence on its reduction. In fact, the speed of the skip free fall, being less than the theoretical one, provides a significant reduction in its kinetic energy, which in turn reduces the value of the dynamic load on pentices.
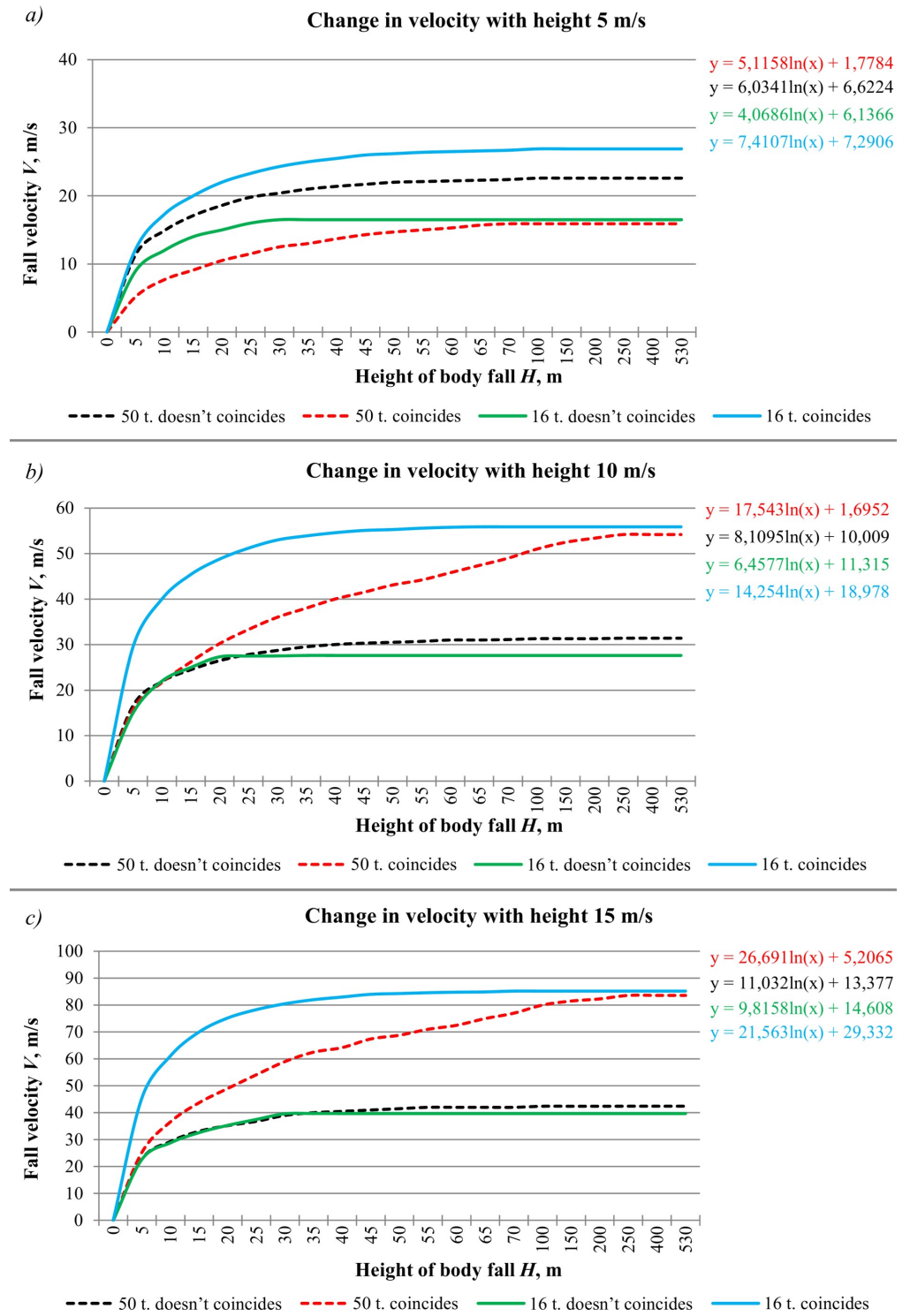

Fig. 2. Change in body's velocity with height.

The research results allowed to substantiate and determine the type and the value of the likely loads for the development of new designs of pentices for sinking an active hoisting shaft, which ensured a reduction in construction time, cost, and material consumption. 


\section{References}

1. V. A. Kovalev, A. I. Kopytov, V. V. Pershin, Coal, 2, 6 (2014)

2. Federal Regulations for industrial safety "Safety rules for coal mines" (Scientific and Technical Center for Research of Industrial Safety Problems, Moscow, 2014)

3. V.V. Pershin, A.I. Kopytov, V.I. Sarychev, Vertical shaft tunneling and sinking (Science, Novosibirsk, 2014)

4. W. J. Kempson, Essays Innovate, 9, 76, (2014)

5. T. Kratz, P. N. Martens, Glückauf, 2, 16 (2015)

6. A. I. Kopytov, V. V. Pershin, Yu. A. Fadeev, A. A. Wetti, Mining Journal, 4, 28 (2019)

7. A. M. Zadorozhniy, V. V. Lipovik, V. Ya. Kozariz, News of the Higher Institutions. Mining Journal, 5, 24 (1979)

8. A. I. Kopytov, M. D. Voitov, A. A. Wetti, Mining Journal, 1, 67 (2015)

9. V. V. Pershin, A. I. Kopytov, M. D. Voitov, I. V. Zhuk, A. A. Wetti // Taishan Academic Forum - Project on mine Disaster Prevention and Control, 1, 21 (2014)

10. V. V. Pershin, A. I. Kopytov, Yu. A. Fadeev, A. A. Wetti, E3S Web Conf., 41, 01016 (2018) 